\title{
First report of Alternaria alternata causing leaf spot on Hosta fortunei in Italy
}

\author{
Angelo Garibaldi ${ }^{1} \cdot$ Giulia Tabone $^{1} \cdot$ Incoronata Luongo $^{2} \cdot$ Maria Lodovica Gullino $^{1}$
}

Received: 16 December 2020 / Accepted: 26 February 2021 / Published online: 22 March 2021

(c) Società Italiana di Patologia Vegetale (S.I.Pa.V.) 2021

Keywords Ornamental plants $\cdot$ Leaf spot $\cdot$ Gardens

In autumn 2019 and spring 2020, small and punctiform light-brown leaf spots were observed on 20 out of 50 20-year-old plants of Hosta fortunei (Liliaceae family) cultivated in a private garden near Biella (Northern Italy). Lesions expanded, affecting a large part of the leaf surface. From the margins of the necrotic tissues olivaceous fungal colonies were consistently isolated. A monoconidial culture on potato carrot media (PCA) produced dark-brown, ovoid or ellipsoid conidia, with 1 to 4 transverse and 0 to 2 longitudinal septa. They measured 10.8 to 36.4 (average $23.1) \times 4.5$ to 16.2 (average 8.1) $\mu \mathrm{m}(\mathrm{n}=50)$. Some of them had a light or brown short beak, 2.1 to 7.2 (average 4.2) $\mu \mathrm{m}$. These morphological characteristics are consistent with the genus Alternaria sp. (Simmons 2007). A PCR was carried out for tefl, endoPG and $r p b 2$ regions of the isolate coded 19/45 (Woudenberg et al. 2015) (GenBank Accession Nos. MW281049; MW281050; MW281051 respectively). A BLASTn analysis exhibited $100 \%$ similarity with the isolate CBS 104.26 of A. alternata for tefl and endoPG (KP125074; KP123995) and $100 \%$ similarity with the ex-type CBS 916.96 for $r p b 2$ (KC584375). Three repeated pathogenicity tests (three plants/test) were carried out by spraying a conidial suspension at a concentration of $1 \times 10^{5}$ conidia/ $\mathrm{ml}(5 \mathrm{ml} /$ plants $)$ on the leaves of three healthy plants of $H$. fortunei. Three plants sprayed with deionized water were used as controls. Plants were covered with a plastic transparent bag and maintained in a greenhouse at $20-25^{\circ} \mathrm{C}$ for 7 days. First symptoms were observed fourteen days after the inoculation, while controls remained healthy. A. alternata was consistently recovered from the infected tissues. According to the USDA-ARS Fungal Database (Farr and Rossman 2020), this is the first report of A. alternata on $H$. fortunei in Italy as well as elsewhere.

\section{References}

Farr DF, Rossman AY (2020) Fungal Databases, U.S. National Fungus Collections, ARS, USDA. Retrieved 29 Oct 2020, from https:// nt.ars-grin.gov/fungaldatabases/

Simmons EG (2007) Alternaria: an identification manual. CBS Biodiversity Centre, Utrecht, The Netherlands

Woudenberg JHC, Seidl MF, Groenewald JZ, De Vries M, Stielow JB, Thomma BPHJ, Crous PW (2015) Alternaria section Alternaria: species, formae speciales or pathotypes? Stud Mycol 82:1

Publisher's Note Springer Nature remains neutral with regard to jurisdictional claims in published maps and institutional affiliations.

Giulia Tabone

giulia.tabone@unito.it

1 Centre of Competence for the Innovation in the Agro-Environmental Sector (AGROINNOVA), University of Torino, Largo Paolo Braccini 2, 10095 Grugliasco Torino, Italy

2 University of Torino, Largo Paolo Braccini 2, 10095 Grugliasco Torino, Italy 